${ }^{22}$ Ryan G, Latimer KM, Dolovich J, Hargreave FE. Bronchial responsiveness to histamine: relationship to diurnal variation of peak flow rate, improvement after bronchodilator, and airway calibre. Thorax 1982; 37:423-9.

${ }^{23}$ Dahlén S-E, Hansson G, Hedqvist P, Björck T, Granstörm E, Dhalén B. Allergen challenge of lung tissue from asthmatics elicits bronchial contraction that correlates with the release of leukotrienes $C_{k}, D_{4}$ and $\mathrm{E}_{4}$. Proc Natl Acad Sci USA 1983;80:1712-6.

${ }^{24}$ Benson MK. Bronchial hyperreactivity. Br $\mathcal{F}$ Dis Chest 1975;69:227-39.

${ }^{25}$ Orange RP, Austen WG, Austen KF. Immunological release of histamine and slow-reacting substance of anaphylaxis from human lung. $\mathcal{F} \operatorname{Exp}$ Med 1971;134:136-48s.

${ }^{26}$ Zoumboulakis D, Anagnostakis D, Albanis V, Matsaniotis N. Steroids in treatment of pertussis. A controlled clinical trial. Arch Dis Child 1973;48:51-4.

27 Anderson SD, Seale JP, Rozea P, Bandler L, Theobald G, Lindsay DA. Inhaled and oral salbutamol in exercise-induced asthma. $A m \operatorname{Rev}$ Respir Dis 1976;114:493-500.

(Accepted 12 fuly 1983)

\title{
Fetal distress and the condition of newborn infants
}

\author{
G S SYKES, PAULA M MOLLOY, P JOHNSON, G M STIRRAT, A C TURNBULL
}

\begin{abstract}
In a prospective audit of the obstetric management of 1210 consecutive deliveries the association was investigated between the need for operative delivery for fetal distress during labour and the condition of the newborn infant. Operative delivery was performed for only $11.5 \%$ of the newborn infants with severe acidosis at birth (umbilical artery pH $<7 \cdot 12$, base deficit $>12 \mathrm{mmol}$ $(\mathrm{mEq}) / \mathbf{1}), \mathbf{2 4} \cdot \mathbf{1} \%$ of those with an Apgar score $<7$ at one minute, and $15.8 \%$ of those with both severe acidosis and a one minute Apgar score $<7$. Most of the infants delivered operatively were in a vigorous condition at birth and did not have severe acidosis. Fetal blood sampling was done in $4.0 \%$ of labours. As none of the fetal blood values were less than $7 \cdot 20$ and only three of the infants sampled in utero suffered severe acidosis at birth, fetal blood sampling would have had to be performed much more often to provide a useful guide to metabolic state at birth. While the large majority of "at risk" fetuses had continuous fetal heart rate monitoring in labour, this had not been provided in $48.7 \%$ of the labours of infants with severe acidosis, $38.7 \%$ of infants with a one minute Apgar score $<7$, and $47.4 \%$ of infants with both severe acidosis and a one minute Apgar score $<7$. Continuous fetal heart rate monitoring was associated with a much higher incidence of operative delivery for fetal distress than was intermittent fetal heart rate auscultation.
\end{abstract}

These results suggest an urgent need to review present methods for assessing the intrapartum condition of the fetus, making the diagnosis of fetal distress, and assessing the condition of the infant at birth.

Nuffield Department of Obstetrics and Gynaecology, John Radcliffe Hospital, Oxford

G S SYKES, MRCOG, research fellow

PAULA M MOLLOY, SRN, SCM, research midwifery sister

P JOHNSON, MB, BS, honorary consultant in clinical physiology

G M STIRRAT, MD, FRCOG, clinical reader in obstetrics and gynaecology

A C TURNBULL, MD, FRCOG, Nuffield professor of obstetrics and gynaecology

Correspondence to: Dr P Johnson.

\section{Introduction}

Fetal distress is a relatively common indication for operative delivery. The diagnosis is usually based on characteristic changes in fetal heart rate assessed by auscultation or electronic recording with, in some cases, low $\mathrm{pH}$ in a fetal blood sample. ${ }^{1-3}$ At this hospital continuous monitoring of fetal heart rate is done largely in only "at risk" labours, as the results of randomised controlled trials of fetal monitoring ${ }^{4-8}$ are not considered to justify a policy of extending continuous fetal heart rate monitoring to all. Analysis of umbilical cord blood samples of at risk newborn infants showed that their acid base state at delivery was not related to the clinical diagnosis of fetal distress, raising doubts about the effectiveness of intrapartum fetal surveillance. Since severe fetal metabolic acidosis due to hypoxia is thought to be important in asphyxial damage in the newborn, ${ }^{3} 9$ and since it was not known how closely clinical diagnosis of fetal distress was associated with severe acidosis at birth or the clinical condition of the newborn infant, a prospective audit of these factors was conducted in 1000 consecutive deliveries managed by routine methods.

\section{Methods}

The clinical condition of newborn infants was assessed by Apgar score and their biochemical condition by measuring umbilical artery blood values. Umbilical cords were double clamped immediately after delivery, samples collected anaerobically into preheparinised polyethylene syringes, and were analysed as soon as possible using an ABL-3 Acid-Base Laboratory (Radiometer, Copenhagen). If immediate analysis was not possible the capped syringes were immersed in crushed ice and stored in the refrigerator. In this study umbilical artery $\mathrm{pH}$ and base deficit were investigated, as they provide a reliable indication of the degree of fetal tissue metabolism at delivery. "Severe acidosis" was defined as being present when both umbilical artery $\mathrm{pH}$ and base excess measurements were one standard deviation below the mean of the population studied.

Patient management was not modified in any way during the audit period. All information was obtained by scrutinising the case notes and stored fetal heart rate recordings. When the primary indication for operative delivery was fetal distress a newborn infant was classified as having had an "operative delivery for fetal distress." The obstetrician's diagnosis of fetal distress was usually based on concern about the fetal heart rate, occasionally on fetal blood $\mathrm{pH}$, and sometimes on other observations. The usual indications for continuous fetal heart rate monitoring were poor obstetric history, hypertension, pre-eclampsia, diabetes, antepartum haemorrhage, intrauterine growth retardation, prematurity, malpresentation, epidural anaesthesia, oxytocin infusion, meconium stained liquor, an auscultated fetal heart rate $<120$ beats/min, $>160$ beats $/ \mathrm{min}$, or with excessive irregularity, "trial of scar," and "trial of labour"; however, the decision about the method of fetal heart rate monitoring was made 
by the obstetrician on duty in the delivery suite. Electronic monitors were available for continuous fetal heart rate monitoring and used with fetal scalp electrodes and external tocodynomometry. In other cases fetal heart rate was assessed by auscultation with a Pinard stethoscope or Doppler ultrasound. Fetal blood samples were obtained when the duty obstetrician considered that there was a clinical indication.

The data were analysed using the hospital CTL8050 computer and the SPSS package of the University of Oxford Computer Centre.

\section{Results}

During 6 April to 17 June 1981 there were 1210 deliveries. Umbilical artery specimens were obtained at 899 of the births. Mean values (1 SD) were pH $7.20(0.08)$, and base deficit $8.33(3.97) \mathrm{mmol}$ $(\mathrm{mEq}) / \mathrm{l}$. Severe acidosis at birth was therefore present when the umbilical artery $\mathrm{pH}$ was less than $7 \cdot 12$ and base deficit greater than $12 \mathrm{mmol} / \mathrm{l}$. Sixty infants delivered by caesarean section before the onset of labour and one delivered by caesarean section during labour for fetal distress but later classified as stillborn were excluded from further analysis. Of these 61 infants, 49 had umbilical artery results; hence 850 infants with umbilical artery results were available for the following analyses.

The table gives the numbers of infants with severe acidosis at birth, one minute Apgar score $<7$, continuous fetal heart rate monitoring,

Newborn infants with umbilical artery results who had severe acidosis, one minute Apgar score < 7, or both, and had continuous fetal heart rate monitoring or intermittent fetal heart rate auscultation distributed according to whether or not there was operative delivery for fetal distress

\begin{tabular}{|c|c|c|c|c|c|}
\hline & \multirow{3}{*}{ Total } & \multicolumn{4}{|c|}{$\begin{array}{l}\text { Operative delivery for } \\
\text { fetal distress }\end{array}$} \\
\hline & & \multicolumn{2}{|c|}{ Yes } & \multicolumn{2}{|c|}{ No } \\
\hline & & No & $0_{0}$ & No & $" 0$ \\
\hline Total & 850 & 73 & $8 \cdot 6$ & 777 & $91 \cdot 4$ \\
\hline Severe acidosis & 78 & 9 & 11.5 & 69 & $88 \cdot 5$ \\
\hline Apgar score $<7$ at $1 \mathrm{~min}$ & 87 & 21 & $24 \cdot 1$ & 66 & $75 \cdot 9$ \\
\hline $\begin{array}{l}\text { Severe acidosis plus Apgar score }<7 \text { at } \\
1 \mathrm{~min}\end{array}$ & 19 & 3 & $15 \cdot 8$ & 16 & $84 \cdot 2$ \\
\hline Continuous fetal heart rate monitoring & 395 & 63 & $15 \cdot 9$ & 332 & $84 \cdot 1$ \\
\hline Intermittent fetal heart rate auscultation & 455 & 10 & $2 \cdot 2$ & 445 & $97 \cdot 8$ \\
\hline
\end{tabular}

and intermittent fetal heart rate auscultation distributed in relation to whether or not they had had an operative delivery for fetal distress. Operative delivery was performed for only $11.5 \%$ of infants with severe acidosis at birth, $24 \cdot 1 \%$ of those with a one minute Apgar score $<7$, and $15.8 \%$ of those with both severe acidosis and a one minute Apgar score $<7$. The 100 operative deliveries for fetal distress in the period included 84 forceps deliveries (including 20 rotational forceps), one ventouse extraction, and 15 caesarean sections. None of the eight babies delivered by caesarean section and only one of the 13 delivered by rotational forceps for "fetal distress" had severe acidosis. Two of the caesarean sections for fetal distress were preceded by fetal blood sampling. Fetal blood sampling was carried out in $34(4.0 \%)$ of the 850 labours. Three of the infants in whom fetal blood sampling was performed had severe acidosis at birth, although in none was the $\mathrm{pH}$ of the fetal blood less than 7.20.

Continuous fetal heart rate monitoring was used in $395(46.5 \%)$ of the 850 labours. Even so, $48(38.7 \%)$ of the 124 newborn infants with a one minute Apgar score $<7,38(48.7 \%)$ of the 78 newborn infants with severe acidosis, and $9(47.4 \%)$ of the 19 newborn infants with both severe acidosis and a one minute Apgar score $<7$ did not have continuous fetal heart rate monitoring. Eleven of the 38 severely acidotic newborn infants who had intermittent fetal heart rate auscultation had antenatal or intrapartum risk factors which should have merited the use of continuous monitoring. These risk factors were: previous caesarean section (one case), poor obstetric history (three), breech presentation (two), oxytocin administration (four), and meconium stained liquor (one). The figure illustrates the relation between operative delivery for fetal distress and severe acidosis, comparing continuous fetal heart rate monitoring with intermittent auscultation. Although operative delivery was more common in cases with continuous fetal heart rate monitoring $(63 / 395 ; 15.9 \%)$ compared with intermittent fetal heart rate monitoring (10/455; $2 \cdot 2 \%$ ), there was little difference between the two groups in the incidence of severe acidosis in the infants at birth. There was a poor relation between operative delivery for fetal distress and severe
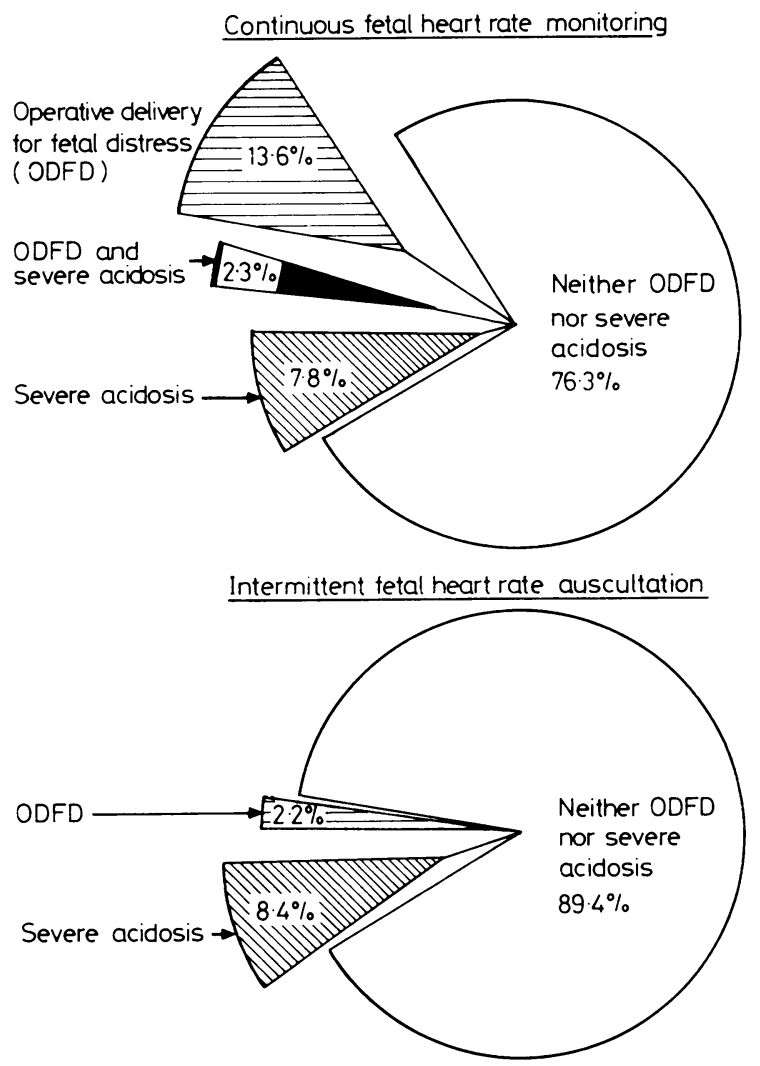

Newborn infants with umbilical artery results divided into two groups according to whether or not there was continuous fetal heart rate monitoring $(46 \%)$ or intermittent fetal heart rate auscultation $(54 \%)$. Number of newborn infants who had severe acidosis or operative delivery for fetal distress in each group shown by relevant sector of circle and expressed as percentage of total number in that group. Number who had both operative delivery for fetal distress and severe acidosis in each group is indicated by overlap of sectors.

acidosis in both groups. None of the infants with intermittent fetal heart rate auscultation and severe acidosis at birth had an operative delivery for fetal distress.

\section{Discussion}

The results of this audit confirm that in our experience the diagnosis of fetal distress usually is not associated with severe acidosis or low Apgar scores. In contrast to many studies, both biochemical and clinical variables were used to assess the condition of newborn infants. While the Apgar scoring system is a popular method of assessing asphyxia, low scores relate poorly to fetal acidosis in labour ${ }^{10}$ and at delivery ${ }^{11}$ and to cerebral palsy in infancy. ${ }^{12}$ The $\mathrm{pH}$ is considered to be the most objective indication of fetal hypoxia during labour, but the prognostic developmental implications of severe acidosis at birth have not been adequately evaluated. A healthy fetus with an activated sympathetic nervous system may be able to respond successfully to a difficult labour, resulting in severe acidosis which is then rapidly reversed after delivery. ${ }^{13}$ On the other hand, a fetus compromised or with retarded growth before the onset of even a normal labour may not be able to adapt adequately. ${ }^{14}$

Many newborn infants with severe acidosis or low Apgar scores did not have antenatal or intrapartum risk factors. It is 
not possible to provide reliable criteria for a selective "high risk" electronic fetal heart rate monitoring policy, and in a "low risk" population there will be unexpected adverse outcomes. ${ }^{15}$ Even so, the use of continuous fetal heart rate monitoring in this study did little to improve the precision in predicting which infants would be born in an adverse condition. This agrees with the findings of randomised controlled trials of fetal monitoring, 4-8 which showed that while the use of electronic fetal heart rate monitoring was associated with an increased incidence of operative deliveries, it was not of certain benefit to fetal wellbeing. Similarly in this study the incidence of operative deliveries was much higher among those newborn infants monitored continuously in labour. It was unlikely that the high incidence of operative delivery for fetal distress with good outcome avoided an even higher incidence of adverse outcome had these labours continued uninterrupted, since the majority of newborn infants with severe acidosis or low Apgar scores at birth had not been considered to have fetal distress.

As none of the infants delivered operatively because of concern about their auscultated fetal heart rates were born with severe acidosis, fetal heart rate auscultation was an insensitive method of assessing the fetal condition and should not be used alone to diagnose fetal distress. Nevertheless, when the continuous fetal heart rate recordings were reviewed retrospectively it was apparent that continuously recorded fetal heart rate patterns had a poor relation to acid base state at birth. While severe acidosis was more frequent after ominous fetal heart rate patterns, it also occurred after normal patterns $(14.8 \%$ of cases). ${ }^{16}$

The indications for fetal blood sampling were not clearly defined. The number of caesarean sections for fetal distress might have been greater had there been electronic fetal heart rate monitoring in all labours and had there not been any fetal blood sampling. Deliveries by caesarean section might have been avoided on those occasions when there was not severe acidosis at birth had fetal blood sampling been used more often to assess the implication of the abnormal fetal heart rate patterns. Most operative deliveries were by forceps. In second stage labour when there was concern about a fetal heart rate pattern it was considered more expedient to perform a forceps delivery than fetal blood sampling. The lack of a reliable means of classifying second stage fetal heart rate patterns weakened the relation between these patterns and the condition at birth-and hence the retrospective prediction of the need for operative intervention. This is of particular concern, as events in the second stage may have serious adverse effects on the condition of the infant at birth (as well as that of the mother).

Of the fetal heart rate recordings, $27 \cdot 1 \%$ considered retrospectively were not suitable for interpretation. This was because of poor quality of the recordings or because monitoring was discontinued more than 30 minutes before delivery. This high figure may be representative of many units. Krebs et al ${ }^{17}$ reported $31.3 \%$ of their 3200 fetal heart rate recordings and Beard et $a l^{3} 9.8 \%$ of their 392 recordings as not suitable for analysis. Not only is poor quality monitoring wasteful but it may increase the risks to the fetus and mother, as erroneous decisions may be made as a result.

It is reasonable to assume that these results are representative of obstetric practice in many units in Britain. The perinatal mortality rate in our unit is one of the lowest in Britain, and the obstetricians on duty for delivery are all of a senior grade. In many British obstetric units continuous fetal heart rate monitoring is carried out only for "at risk" fetuses, and some do not have facilities for fetal blood sampling. ${ }^{18}$ These data show that current methods for intrapartum fetal monitoring are inadequate. While in Britain the Short committee ${ }^{19}$ appeared to be satisfied with the widespread use of electronic fetal heart rate monitoring alone, the United States NIH Task Force on Intrapartum Fetal Monitoring ${ }^{2}$ identified the need to develop non-invasive methods of fetal monitoring with greater precision for the detection of asphyxia. Such methods surely would resolve much of the antipathy to fetal monitoring.
For the present the only means of increasing the precision of fetal heart rate monitoring in detecting fetal distress is more frequent but sensible usage of fetal blood sampling. ${ }^{20}$ Routine umbilical cord blood analysis should be encouraged as a simple means of auditing the incidence of severe acidosis at birth and the value of clinical management in detecting or preventing it. There are obvious problems with both selective and universal policies for continuous fetal heart rate monitoring. It is the responsibility of individual obstetric units to formulate their own policies as governed by their own resources and populations and to audit the value of their own obstetric management. Nevertheless, an overriding impression from our analysis is that there is very little appreciation by clinicians for the dynamic nature of fetal adaptability to compromise and its reversibility. This is particularly important in modern obstetrics, where induction, augmentation, and epidural anaesthesia are common.

We are indebted to the consultants, junior medical staff, general practitioners, and hospital and community midwives of the John Radcliffe Hospital for their cooperation and help. This study was supported by DHSS grant RE1052/46.

\section{References}

${ }^{1}$ Goodlin RC. History of fetal monitoring. Am $\mathcal{F}$ Obstet Gynecol 1979;133 : 323-52.

${ }^{2}$ Zuspan FP, Quilligan EJ, James JD, van Geisn HP. Practices of intrapartum fetal obstetrics: the role of electronic fetal monitoring. $A m \mathcal{F}$ Obstet Gynecol 1979;135:287-91.

${ }^{3}$ Beard RW, Filshie GM, Knight CA, Roberts GM. The significance of the changes of the continuous fetal heart rate in first stage labour. fournal of Obstetrics and Gynaecology of the British Commonwealth $1971 ; 78: 865-81$.

${ }^{4}$ Havercamp AD, Thompson HE, McFee JG, Cetrulo C. The evaluation of continuous fetal heart rate monitoring in high risk pregnancy. $A m \mathcal{F}$ Obstet Gynecol 1976;125:310-7.

${ }^{5}$ Renou P, Chang A, Anderson I, Wood C. Controlled trial of fetal intensive care. Am $\mathcal{F}$ Obstet Gynecol 1976;126:470-6.

${ }^{6}$ Kelso IM, Parsons RJ, Lawrence GF, Arora SS, Edmonds DK, Cooke ID. Continuous fetal heart rate monitoring in labor. $A m$ f Obstet Gynecol 1978;131:526-31.

${ }^{7}$ Havercamp AD, Orleans M, Langendoerfer S, McFee J, Murphy J, Thompson HE. A controlled trial of the differential effects of intrapartum fetal monitoring. Am f Obstet Gynecol 1979;134:399-412.

${ }^{8}$ Wood C, Renou P, Oats J, Farreli E, Beischer N, Anderson I. A controlled trial of fetal heart rate monitoring in a low risk obstetric population. Am f Obstet Gynecol 1981;141:527-624.

${ }^{9}$ Saling E, Schneider D. Biochemical supervision of the fetus during labour. Fournal of Obstetrics and Gynaecology of the British Commonwealth $1967 ; \mathbf{7 4}: 799-811$.

${ }^{10}$ Weber $\mathrm{T}$. The validity of discontinuous $\mathrm{pH}$ measurements on fetal blood and of cardiotocography in predicting neonatal Apgar scores. Dan Med Bull $1979 ; 26: 186-91$.

${ }^{11}$ Sykes GS, Molloy P, Johnson P, Gu W, Ashworth F, Stirrat GM, Turnbull AC. Do Apgar scores indicate asphyxia ? Lancet $1982 ; \mathrm{i}: 494-5$.

${ }_{12}$ Nelson KB, Ellenberg JH. Apgar scores as predictors of chronic neurologic disability. Pediatrics $1981 ; 68: 36-44$.

${ }^{13}$ Lagercrantz H. Asphyxia and the Apgar score. Lancet 1982;i:966.

${ }^{14}$ Kenny JD, Garcia-Prats JA, Hilliard JL, Corbes JA, Rudolf JA. Hypercapnia at birth: a possible role in the pathogenesis of intra-ventricular hemorrhage. Pediatrics 1978;62:465-7.

${ }^{15}$ Wilson RW, Shifrin BS. Is any pregnancy low risk? Obstet Gynecol $1980 ; 55: 653-6$.

${ }^{16}$ Low IA, Cox MJ, Karchmar EJ, McGrath MJ, Pancham SR, Piercy WN. The prediction of intrapartum fetal acidosis by fetal heart rate monitoring. Am $\mathcal{F}$ Obstet Gynecol 1981;139:299-305.

${ }^{17}$ Krebs HB, Petres RE, Dunn LJ, Jordann HVF, Segreti A. Intrapartum fetal heart rate monitoring. III Association of meconium with abnormal fetal heart rate patterns. Am F Obstet Gynecol 1980;137:936-43.

${ }^{18}$ Gillmer MDG, Combe D. Intrapartum fetal monitoring practice in the United Kingdom. Br $\mathcal{F}$ Obstet Gynaecol 1979;86:753-8.

${ }^{19}$ Social Services Committee on Perinatal and Neonatal Mortality. Second report 1978-80. London: HMSO, 1980.

${ }^{20}$ Zalar RW, Quilligan EJ. The influence of scalp sampling on the cesarean section rate for fetal distress. Am F Obstet Gynecol 1979;135:239-46.

(Accepted 20 fuly 1983) 